\title{
Transforming City Governments Through IT
}

Wesley J. Meier, University of Detroit Mercy, USA

Gregory W. Ulferts, University of Detroit Mercy, USA

Terry L. Howard, University of Detroit Mercy, USA

\begin{abstract}
City governments have implemented the use of technology in an attempt to enhance their service and operational capabilities. The efforts of the past were well intended, however, the disjuncture of these combined efforts have created "islands of information" within their administrative infrastructure. Many corporations today face similar issues that city governments do; decentralized IT infrastructure, dwindling cash flows, and overall operational inefficiency. For medium sized urban centers to have a chance for a brighter future it is absolutely imperative to effectuate change at all levels of city government. The kind of change necessary is not only in an operational capacity, but that of a culture shift as well. Information technology, when used appropriately, has the ability to be the catalyst for the kind of change required to resurrect communities.
\end{abstract}

Keywords: Government; Technology; Governance

\section{GOVERNANCE}

ithout central governance of the IT function, administrative infrastructures have grown into an entity
that increases costs and inhibits the free flow of information between departments. Projects and
expenditures alike have grown to a point where they have become detrimental to the balance sheet as well as operational efficiency and effectiveness. As information systems' spending continues to increase, in some cases at an alarming rate, the inability to articulate the value information systems provided within a specific organization becomes an increasingly important issue. It has become even more formidable as information technology has become more disbursed throughout the entire organization. In the current environment some organizations have a hard time just determining the total amount being spent on information technology.

The ability of leadership to make quality decisions has been limited, not only because of the decentralized IT infrastructure, but because of the various bureaucratic deficiencies related to the flow of information. Principles contained in Project Management, Optimization, Six Sigma, and Process Improvement are not being utilized as standard operating procedures within medium sized city governments. Decision making should be approached with logic and objectivity. Leadership should comprehensively understand its value to an organization. Furthermore, those who govern the decision-making process have a greater responsibility to leverage the potential benefits IT can provide to stakeholders.

A centralized infrastructure that is guided by competent IT leadership will make it possible for data to be collected, analyzed, and deliberated over with the assistance of qualitative and quantitative models. A centralized governance committee comprised of a Chief Information Officer and IT experts need to be embedded within city governments, and report directly to the executive office. The presence of an IT steering committee will enhance the capability of the IT function to become a revenue generator, a cost minimizer, and a service improver.

\section{LEGACY MINDSETS}

In simple terms, people are creatures of habit. The employees of many cities have become accustomed to a particular IT organizational philosophy, and to effectuate change, it needs to be overcome. Even corporations that are defined as technology firms experience these issues, IBM for example, "had a stagnant business model that did not work for the industry, coupled with a "legacy" mindset within the organization" (IBM's Decade of 
Transformation, 2009).

Legacy mindset limitations within an organization can be quite detrimental, especially when trying to implement new strategy. These legacy mindsets are not limited to employee processes and procedures, but to the infrastructure itself. While infrastructure alone can't convey sustainable proprietary advantage, businesses that remain chained to a legacy of incompatible and inflexible proprietary infrastructures also find themselves at a significant strategic disadvantage as they attempt to keep pace with increasingly shorter cycles of innovation, productivity, and returns (Applegate, Austin \& Soule, 2009).

Although centralizing IT infrastructures will provide immediate benefits, it will not solve the problem of numerous and incompatible legacy systems. This issue alone generates a great deal of labor hours from manual data entries and corrections. It will become necessary for leadership to address the issue of standardization and an open architecture platform that flows through all departments directly to decision makers.

\section{MANAGEMENT TOOLS}

The integration of Project Management (PM) methodologies, Six Sigma, and Process Improvement (PI) is necessary to successfully complete the process of centralizing Procurement and IT. There are significant benefits to the use of these tools; they include reduced management costs, standardized project management processes, and improved management efficiency and effectiveness (The AtekPC Project Management, 2009).

Integrating the use of these management tools has the potential to save significant amounts of money both in IT and across all administrative departments. As an example, according to the Six Sigma Academy, Black Belts save companies approximately $\$ 230,000$ per project and can complete four to 6 projects per year. General Electric, one of the most successful companies implementing Six Sigma, has estimated benefits on the order of $\$ 10$ billion during the first five years of implementation (iSixSigma, 2009).

One of the first steps required to moving towards operational efficiency and effectiveness within the IT function is the use of Project Management methodologies. Outside of the immediate benefits discussed, there is one disadvantage to adopting these management tools. It can be quite expensive (and time consuming) to train existing employees and it can also be costly to bring consultants into the equation.

Good IT governance can increase the effectiveness of an enterprise by organizing IT assets so as to optimally enable business goals, protecting enterprise investments in IT, including systems and networks, assuring security and reliability of strategic information, addressing IT-centric business issues such as enterprise resource management, and ensuring appropriate management of enterprise information assets (Applegate, Austin \& Soule, 2009). Successful IT oversight requires an important doctrine to be observed: technology is an investment, not an expense. All too often the fate of IT within an organization is left to be decided by the Finance Department. This is a critical error. The IT Executive Steering Committee should report directly to the executive office, by way of a Chief Information Officer. This requires medium sized urban centers to adjust current structures in order to chart the future course of transformation.

\section{SUMMARY}

If medium sized urban centers are going to achieve efficiency and effectiveness, then it is absolutely imperative to effectuate change at all levels of city government. This requires leadership that can implement appropriate governance structures, effectuate change, and utilize modern management tools.

\section{AUTHOR INFORMATION}

Mr. Wesley J. Meier received his MBA/MSCIS from the University of Detroit Mercy. He served as a graduate assistant for the College of Business Administration and Decision Sciences discipline, was the President of the College of Business Administration's Graduate Student Advisory Board, and is also a member of the President's Council. He was awarded a Leadership Medallion from the UDM Institute for Leadership and Service. Mr. Meier is 
a student member of the International Association of Jesuit Business Schools Honor Society as well as Alpha Iota Delta, the International Honor Society in the Decision Sciences and Information Systems. Email: meierwj@udmercy.edu

Dr. Gregory W. Ulferts is a Professor of Decision and Systems Sciences in the College of Business Administration at the University of Detroit Mercy. His scholarly activities have included research and publication on various topics related to management information systems, financial management, decision sciences, small business administration, and international business. Dr. Ulferts has served as a consultant in business and government in areas such as strategic and technology planning, operations and procurement management, analysis and design of systems, and business development. Email: ulfertgw@udmercy.edu

Mr. Terry L. Howard works with Business Leadership Network of Michigan and serves as the Director of the Leadership and Economic Independence program, working with 14-26 aged-individuals who have challenges. Mr. Howard has MBA/MSCIS degrees from the University of Detroit Mercy and has certification in Security Information. He is a member of the National Honor Society, Alpha Iota Delta. Mr. Howard is a motivational speaker and has spoken to local organizations and to national groups. He has published papers nationally in professional and academic journals. Email: howardtl@udmercy.edu

\section{REFERENCES}

1. Applegate, L., Austin, R., \& Collins, E. (2005). IBM's Decade of Transformation: Turnaround to Growth. Harvard Business School Case 805-130.

2. Applegate, L.M., Austin, R., \& Soule, D. (2009). Corporate Information Strategy and Management (pp. 106). New York: McGraw-Hill Irwin.

3. Hupp, J., Keil, M., \& McFarlan, F. Warren. (2007). The AtekPC Project Management Office. Harvard Business School Case 308-049.

4. iSixSigma. (December 2009). Retrieved December 10, 2009, from iSixSigma: www.iSixSigma.com 


\section{NOTES}

